\title{
¿QUEDA ESPACIO PARA CRECER? OPORTUNIDADES PARA EL COMERCIO AGROALIMENTARIO EN EL CONTEXTO DE LA MODERNIZACIÓN DEL ACUERDO DE ASOCIACIÓN ENTRE LA UE Y CHILE
}

\author{
Bruno Henry de Frahan \\ Université catholique de Louvain, Bélgica \\ Christopher A. Hartwell \\ Bournemouth University, Reino Unido \\ Kozminski University, Polonia \\ Alberto Valdés \\ Pontificia Universidad Católica de Chile, Chile
}

\begin{abstract}
Resumen: El Acuerdo de Asociación del año 2002 entre la Unión Europea (UE) y Chile fue, para ese momento, el acuerdo comercial más extenso del mundo. Con negociaciones en curso en torno a una modernización del Acuerdo, este artículo examina las posibles oportunidades adicionales de comercio en productos agrícolas y alimentos entre Chile y la UE. Por medio del uso de estadísticas de co-
\end{abstract}

Bruno Henry de Frahan es Professor of Agricultural Economics and Policy, Université Catholique de Louvain, Bélgica. Dirección: 1, Place de l'Université. B-1348 Louvain-la-Neuve, Bélgica. Email: bruno.henrydefrahan@uclouvain.be.

Christopher A. Hartwell es Professor of Financial Systems Resilience, Bournemouth University, Reino Unido, y Professor of International Management, Kozminski University, Polonia.

Alberto Valdés es PhD en economía, LSE. Investigador asociado, Departamento de Economía Agraria, Pontificia Universidad Católica de Chile, Chile. 
mercio y entrevistas clave, trazamos el desarrollo del comercio entre Chile y la UE para los productos agroalimentarios, tanto en términos absolutos como relativos, desde la entrada en vigencia del Acuerdo de Asociación entre la UE y Chile en 2003. Concentrándonos en los principales impulsores de este desarrollo comercial, en este artículo se identifican nuevas oportunidades de comercio que, posiblemente, podrían acompañar la modernización del Acuerdo de Asociación UE-Chile.

Palabras Clave: comercio agrícola, Acuerdo Comercial entre UE y Chile agroalimentario, Acuerdo de Asociación

RECIBIDO: junio 2019 / ACEPTADO: diciembre 2019

\section{ROOM TO GROW? OPPORTUNITIES IN AGRI-FOOD TRADE IN A MODERNISED EU-CHILE ASSOCIATION AGREEMENT}

Abstract: The 2002 Association Agreement between the European Union (EU) and Chile was the most extensive trade agreement in the world at that time. With negotiations underway for a modernisation of the Agreement, this paper examines the possible additional trade opportunities in agricultural and food products between Chile and the EU. Using trade statistics and key interviews, we trace the development of trade in agri-food products between Chile and the EU since the entry into force of the EU-Chile Association Agreement in 2003 , both in absolute and relative terms. Focusing on the main drivers in this trade development, we identify new trade opportunities that could plausibly accompany the modernisation of the EU-Chile Association Agreement.

KEYwords: agricultural trade, trade agreement between EU-Chile, Agri-food, Association Agreement

ReCeIved: June 2019 / AcCEPTED: December 2019

\section{INTRODUCCIÓN}

E $n$ el contexto de la modernización del Acuerdo de Asociación del año 2002 entre la Unión Europea (UE) y Chile, este artículo analiza el desarrollo comercial y, en particular, la evolución del comercio de productos agrícolas y de alimentos entre Chile y la UE desde el año 2000. Nuestro objetivo central es descubrir los principales impulsores de este desarrollo, identificando así las oportunidades de comercio que una modificación del Acuerdo de Asociación de 2002 podría crear para 
ambas partes. Para analizar cómo se ha desarrollado el comercio en productos agrícolas y alimentarios entre Chile y la UE, se calcularon indicadores de comercio, relativos y absolutos, por medio de las estadísticas de comercio de las Naciones Unidas, de Eurostat y del Ministerio de Agricultura de Chile. Para identificar las oportunidades comerciales de los productos agrícolas y alimentarios ahondamos en los principales impulsores comerciales del comercio agroalimentario entre las dos partes, aplicando entrevistas para corroborar el análisis cuantitativo. La conclusión de este artículo es que, de hecho, ambas partes cuentan con margen para crecer en su comercio agroalimentario en la medida en que cualquier modernización del Acuerdo de Asociación abarque también los problemas que a la fecha han contenido al comercio: una mayor liberalización de aranceles, en particular de parte de la UE; una reducción de las barreras no arancelarias (BNA) por ambas partes, especialmente en el ámbito de las medidas sanitarias y fitosanitarias (SFS); y una conciliación de las diferencias entre las dos partes en relación a la especificación de las reglas de origen y a la protección de las indicaciones geográficas. Solo sobre el compromiso de hacer del Acuerdo de Asociación entre Chile y la UE, una vez más, un acuerdo de frontera, que abarque una liberalización de amplia base, puede alcanzarse el potencial comercial entre las dos partes identificado en este artículo.

El resto del texto se desarrolla del siguiente modo. La segunda sección pone en contexto las motivaciones que condujeron a la modernización del Acuerdo de Asociación de la UE y Chile del año 2002. La tercera sección traza el desarrollo comercial entre la UE y Chile para los productos agrícolas y los alimentos desde la entrada en vigencia del Acuerdo de Asociación UE-Chile en 2003, y bosqueja los principales impulsores de este desarrollo comercial. La cuarta sección identifica las oportunidades que podría crear para ambas partes una modernización del Acuerdo de Asociación del año 2002. Por último, en la sección final se presentan las conclusiones.

\section{CONTEXTO}

Al momento de su cierre, en el año 2002, el Acuerdo de Asociación (AA) entre la Unión Europea (UE) y Chile era considerado a la fecha el acuerdo más comprehensivo alguna vez firmado por la UE con un 
tercer país. El componente comercial del Acuerdo de Asociación abarcó un amplio set de disposiciones, muchas de las cuales nunca habían sido incluidas en acuerdos comerciales previos: importantes y rápidas disposiciones arancelarias, compromisos de liberalización para el comercio de servicios, disposiciones innovadoras para facilitar el comercio, disposiciones para medidas sanitarias y fitosanitarias (SFS) que superaban las reglas acordadas por la Organización Mundial de Comercio, y protección de las indicaciones geográficas (IG) -incluyendo la denominación de origen entre los compromisos con los derechos de propiedad intelectual multilaterales reestablecidos en el AA (OJEC 2002). Este fue también el primer acuerdo en pasar por el procedimiento de evaluación de impacto ambiental para identificar las implicancias de las medidas comerciales en el desarrollo económico, social y medioambiental de ambas partes. Probablemente fue una combinación de factores, como la apertura económica de Chile y la estructura de sus relaciones económicas con la UE, la que permitió que este tipo de acuerdo fuera más allá de los acuerdos sustraídos con otras terceras partes, aun cuando la racionalidad económica de un acuerdo tan amplio entre las dos partes era débil (García 2011). El hecho de que menos productos agrícolas sensibles fuesen excluidos de las negociaciones también contribuyó a hacerlas avanzar (Dür 2007).

El impacto del AA a lo largo de distintas métricas ha sido impresionante, con modelamientos posteriores que muestran que Chile ha sido, sobre el neto, un beneficiario de la liberalización del acuerdo en varias categorías agrícolas (Jean et al. 2014). En particular, el acuerdo parece haber elevado el ingreso del trabajo agrícola en Chile (Valdés y Foster 2018), fomentando también diálogos sobre sustentabilidad medioambiental entre los exportadores chilenos y los consumidores y proveedores de la UE, y reforzando las tendencias chilenas hacia iniciativas más verdes (Borregaard 2004). Respecto de su principal objetivo, elevar el volumen del comercio agrícola y de alimentos entre Chile y la UE, los resultados han sido variados. Sin embargo, el volumen comercial no ha alcanzado las predicciones de las estimaciones previas (Nowak-Lehmann et al. 2007). Como muestra el Gráfico 1, la crisis financiera global, en particular, creó una clara recesión de la cual en ambos lados han luchado por resarcirse. 
Gráfico 1. IMPORTACIONES Y EXPORTACIONES AGRÍCOLAS Y DE ALIMENTOS DE LA UE-28 CON CHILE, 2000-2018

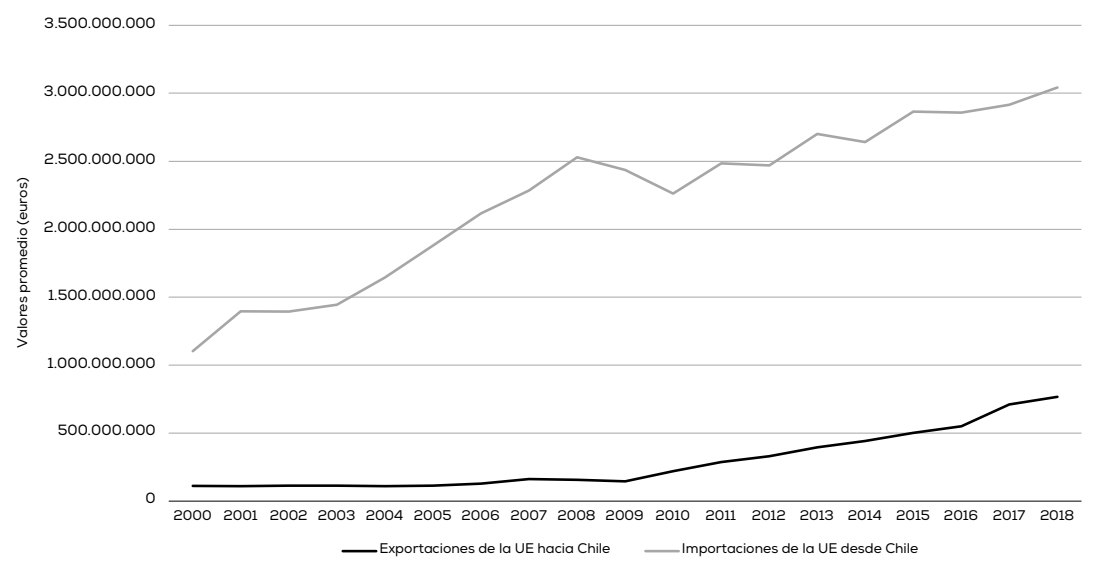

Fuente: Eurostat Comext.

De hecho, aun cuando la entrada en vigencia del Acuerdo de Asociación en el año 2003 mejoró el acceso a mercados para las exportaciones agrícolas y de alimentos desde Chile hacia la UE, todavía existen asuntos pendientes, los que se manifiestan en la incompleta liberalización de la agricultura y en los subsectores de alimentos. Más prominentemente, aún existen 502 líneas arancelarias, de entre las 2.354 líneas arancelarias de productos agrícolas y de alimentos $(21 \%$ del total) del Harmonised Commodity Description and Coding System (HS) del año 2002, que fueron excluidas del importe gradual de liberalización del AA; y 110 líneas arancelarias más (4,7\% del total) que solo se encuentran bajo liberalización parcial (ECORYS-CASE 2017). Más aún, en algunas categorías sensibles de productos agroalimentarios todavía existen restricciones específicas a las importaciones de la UE desde Chile, como los productos cárnicos, los lácteos y cereales, algunas frutas y vegetales, los productos de confitería, el aceite de oliva y los productos pesqueros. Un estudio realizado a principios de la década de 2000 concluyó que medidas no-arancelarias (MNA), como las relacionadas con barreras técnicas al comercio (BTC) y las medidas sanitarias y fitosanitarias (SFS), entorpecían los flujos comerciales entre Chile y 
la UE en productos agrícolas específicos, como la carne, la fruta fresca y los vegetales (Kjöllerström 2006). En el siguiente análisis examinamos en qué medida estas MNA aún representan barreras comerciales significativas.

Largamente dilatado, el problema de una incompleta liberalización entre la UE y Chile se ha ido haciendo más importante debido a que, en general (pero particularmente en los productos agroalimentarios), el escenario comercial global ha cambiado sustancialmente desde el año 2003. De hecho, la UE y Chile, de forma independiente, han celebrado varios acuerdos comerciales con terceros países a fin de facilitar el comercio agrícola y mejorar la inversión, acuerdos que han tenido el potencial de desviar el comercio agrícola entre las dos partes y hacia otros lugares. En particular, la UE se ha movido hacia una 'nueva generación' de acuerdos de libre comercio (ALC), enfocándose en economías de alto potencial exportador como, por ejemplo, Corea del Sur en 2009 y Singapur en 2012. Estos nuevos ALC pueden ser WTO-plus, en tanto poseen un calendario ambicioso de eliminación de aranceles, o ser WTO-extra, en tanto se expanden hacia la facilitación del comercio de servicios, la liberalización y protección de la inversión, y la superación de las barreras no-arancelarias (Horn et al. 2010).

En el continente americano, la UE también ha celebrado exhaustivos tratados de libre comercio con Colombia y Perú (a lo que Ecuador accedió en 2017) y un acuerdo de asociación con América Central (Costa Rica, Guatemala, El Salvador, Honduras, Nicaragua y Panamá) en 2012. Desde entonces se han alcanzado 'principios de acuerdo' para la parte comercial de un Acuerdo Global modernizado con México en 2018 y con el Mercosur en 2019. El Acuerdo Económico y Comercial Exhaustivo entre la UE y Canadá (AECE) entró provisionalmente en vigencia en septiembre del año 2017. Desde 2013, la UE ha estado también en negociaciones con Estados Unidos (EEUU) por la denominada Asociación Transatlántica de Comercio e Inversiones, aunque actualmente su estatus se encuentra en espera debido a los desarrollos políticos acontecidos en ambos lados del Atlántico. Mientras tanto, en abril de 2019, el Consejo de la UE aprobó dos mandatos para un acuerdo menos ambicioso con EEUU respecto de la eliminación de aranceles para los bienes industriales y las evaluaciones de conformidad. Por otro lado, en febrero de 2018 entró en vigencia un Acuerdo de Asociación Econó- 
mica con Sudáfrica, mientras que el Acuerdo de Asociación Económica entre la UE y Japón entró en vigencia en febrero de 2019.

También desde el lado chileno, a partir de la celebración del Acuerdo de Asociación del año 2002, el país se ha estado moviendo hacia la elaboración de acuerdos comerciales, habiendo firmado tratados bilaterales con el Área de Libre Comercio Europeo, Corea del Sur y EEUU en 2004, con China y Nueva Zelanda en 2006, con India y Japón en 2007 y con Australia, Colombia y Perú en 2009. Como parte de este impulso hacia la liberalización, en 2011 Chile se sumó a la Alianza del Pacífico (la que actualmente incluye a Colombia, México y Perú) con el objetivo de reducir las barreras comerciales y de promover la integración regional. El protocolo comercial de la Alianza del Pacífico entró en vigencia en abril de 2016. En febrero de 2016, Chile firmó también el Acuerdo Transpacífico de Cooperación Económica (TPP, por su sigla en inglés) con otros 11 países de la costa del Pacífico, con el objetivo de promover el crecimiento económico y el empleo. El acuerdo del TPP contenía, adicionalmente, medidas para disminuir tanto las barreras arancelarias como las no-arancelarias al comercio y establecía un mecanismo de solución de disputas inversor-Estado. Después de que EEUU retirara su firma en enero de 2017, las 11 naciones restantes negociaron un nuevo acuerdo comercial denominado Tratado Integral y Progresivo de Asociación Transpacífico (CPTPP, por su sigla en inglés), el que incorporó la mayoría de las provisiones del TPP, y que entró en vigencia en diciembre de 2018. Chile es también miembro, desde el año 1994, del Foro de Cooperación Económica Asia-Pacífico (APEC, por su sigla en inglés), un foro intergubernamental para las 21 economías pertenecientes a la costa del Pacífico que promueven el libre comercio en la región del Asia-Pacífico.

En la medida en que los acuerdos actuales y los propuestos vayan más allá de las ahora anticuadas provisiones del componente comercial del Acuerdo de Asociación entre la UE y Chile de 2002, presionando por una liberalización agrícola más expansiva, pareciera que las preferencias comerciales en bienes agrícolas entre la UE y Chile están, probablemente, en riesgo de perder su relevancia y atractivo. Esto, a su vez, puede dejar al comercio agrícola y de productos alimenticios entre ambas partes sujeto a una sostenida erosión durante los próximos años. Reconociendo esta eventualidad, la UE ha liderado un intento por 
modernizar el componente comercial del AA, poniendo un foco particular en la superación de las aún prevalecientes barreras al comercio de productos agrícolas y alimentarios sensibles y en los flujos de inversión hacia el sector (ECORYS-CASE 2017).

\section{EL DESARROLLO COMERCIAL DE PRODUCTOS AGROALIMENTARIOS ENTRE CHILE Y LA UE DESDE 2000}

\section{El desarrollo bilateral del comercio agroalimentario en estadísticas}

Es difícil subestimar en la economía chilena la importancia de las exportaciones de productos agrícolas (incluidos los forestales, y de caza y pesca) y de alimentos (incluyendo las bebidas y los productos tabacaleros). En términos de cifras generales, según el Banco Mundial los productos agrícolas y los alimentos abarcan alrededor del $9 \%$ del producto interno bruto del país, y sus exportaciones alcanzan el $28 \%$ del valor total de las exportaciones de bienes y servicios de Chile (20,1 billones de dólares) en el año 2016 (ver sección 2). ${ }^{1}$ El grado de contribución del sector agroalimentario chileno a toda la economía aún puede ser más grande si, como se destaca en Foster y Valdés (2015), se consideran importantes forward y backward linkages a lo largo de toda la economía.

En términos absolutos, tanto para la UE como para Chile, entre 2003 y 2018 el comercio bilateral de productos agrícolas y alimentarios ha crecido a una tasa promedio anual de un $4 \%$ en las importaciones de la UE desde Chile, alcanzando los 3.042 billones de euros en 2018, y a una tasa aún más impresionante del 14,3\% para las exportaciones desde la UE hacia Chile, alcanzando 767 billones de euros en 2018 (de acuerdo a la base de datos de la Eurostat Comext). ${ }^{2}$ Es posible, sin embargo,

\footnotetext{
${ }^{1}$ El sector agrícola corresponde a las divisiones de la 1 a la 5 del Estándar Internacional de Clasificación Industrial (ISIC, por su sigla en inglés), y el sector de alimentos corresponde a las divisiones 15 y 16 de la misma clasificación. Para las exportaciones, el sector agrícola consta de la sección 2 del Estándar Internacional de Clasificación Comercial (SITC, por su sigla en inglés), y el sector de alimentos consta de las mercancías en las secciones 0,1 y 4, y la división 22 de la misma clasificación.

${ }^{2}$ La base de datos Eurostat Comext proporciona estadísticas de comercio con la UE en tanto socio comercial declarado, lo que implica que las estadísticas de comercio son entregadas en términos de las importaciones de la UE desde Chile y de las exportaciones de la UE hacia Chile.
} 
distinguir dos períodos para las importaciones y las exportaciones de la UE en productos agrícolas y alimentarios (ver Gráfico 1):

- Para las importaciones, un primer período va de 2003 a 2008, durante el cual las importaciones de la UE desde Chile subieron a una tasa promedio anual de un 11,2\%; y un segundo período, entre 2008 y 2018, durante el que las importaciones de la UE subieron a una tasa promedio anual más pequeña, de un $2,4 \%$, teniendo como resultado la débil expansión reciente de las importaciones de la UE de productos agrícolas y alimentarios desde Chile.

- Para la exportaciones, un primer período va desde el año 2003 a 2009, durante el cual las exportaciones de la UE hacia Chile subieron a una tasa promedio anual del $6,5 \%$; y un segundo período, entre el año 2009 y 2018, durante el cual las exportaciones de la UE subieron a una tasa promedio anual más grande, de un $16,8 \%$, resultando en la reciente expansión, mucho más fuerte, de las exportaciones de productos agrícolas y alimentarios desde la UE hacia Chile.

Estas tasas de crecimiento promedio anual de un $4 \%$ y un $14,3 \%$, observadas, respectivamente, para las importaciones y exportaciones de la UE de productos agrícolas y alimentarios desde Chile durante todo el período a partir de 2003, de hecho han sido mucho más rápidas que las tasas de un $0,2 \%$ y un $8 \%$ en las importaciones y exportaciones para todos los bienes de la UE con Chile durante el mismo período (no graficado aquí). También hay dos períodos claramente distintos para el total de las importaciones de la UE desde Chile: un primer período va desde el año 2003 al 2007, durante el cual el total de las importaciones de la UE creció a una tasa promedio anual del $23,7 \%$; y un segundo período va desde el año 2007 al 2018, durante el cual el total de importaciones de la UE descendieron a una tasa promedio anual del 3,2\%.

En términos relativos, en comparación con el comercio con el resto del mundo, y utilizando índices de comercio relativos (ICR) para eliminar indiscriminadamente el efecto de los cambios específicos del país sobre los flujos comerciales (véase el Apéndice en referencia a la metodología), las exportaciones chilenas de productos agrícolas y de alimentos a la UE mejoraron desde el comienzo del Acuerdo hasta el año 2009, aunque a partir de ahí y hasta 2018 fueron a la baja; mientras que las exportaciones de productos agrícolas y alimentarios de la UE hacia Chile fueron en constante declive hasta el año 2008, para luego ir 
en aumento hasta 2017 (ver Gráfico 2). Estos resultados implican que la UE es un destino mucho más buscado para las exportaciones de productos agrícolas y alimentarios de Chile en comparación con el resto del mundo, pero también que esta preferencia comercial desde 2010 ha ido en declive y desde 2014 desaparece. De hecho, la participación de las exportaciones agroalimentarias chilenas en la UE se incrementó desde un $21 \%$ en 2002 , a un $25 \%$ en 2008 , y luego disminuyó a un $18 \%$ en 2018 (ver Gráfico 3). Esta transformación en la participación de las exportaciones se debe, principalmente, a la creciente participación de las exportaciones agroalimentarias chilenas en China, las que han aumentado desde un $7 \%$ en 2008 a un $24 \%$ en 2018. Más relevante aún: los resultados del ICR también sugieren que Chile se ha vuelto un destino más importante para las exportaciones de productos agrícolas y alimentarios de la UE en comparación con el resto del mundo. Sin embargo, al aplicar un ICR al total de las exportaciones de la UE, resulta una imagen distinta: el total de las exportaciones de la UE a Chile, en relación con el resto del mundo, disminuyeron progresivamente durante todo el período comprendido entre 2003 y 2018.

Gráfico 2. ÍNDICES DE COMERCIO RELATIVO DEL COMERCIO AGRÍCOLA Y DE ALIMENTOS (HS 01-24) ENTRE LA UE Y CHILE, 2000-2018 $(2003=100)$

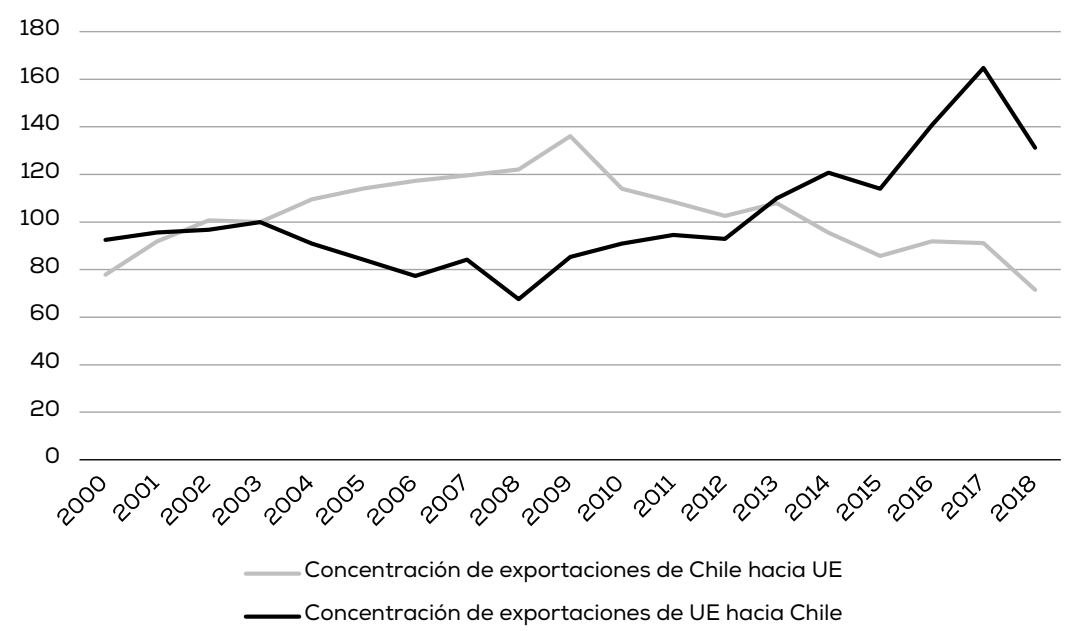

Fuente United Nations Comtrade. 
Gráfico 3. PARTICIPACIÓN DE LAS EXPORTACIONES CHILENAS AGRÍCOLAS Y DE ALIMENTOS EN UE, EEUU, CHINA, JAPÓN, BRASIL Y EL RESTO DEL MUNDO, 20002018 (PORCENTAJES)

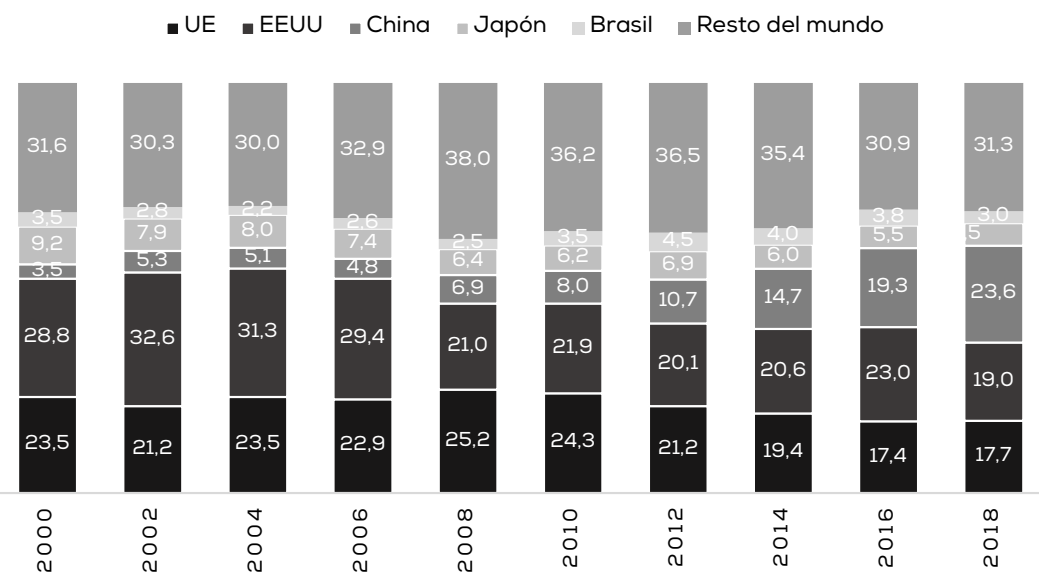

Fuente: Odepa.

En 2018, los productos agrícolas y alimentarios alcanzaron el 36\% del valor total de las importaciones de la UE desde Chile, aunque solo dan cuenta del $7 \%$ del valor total de las exportaciones desde la UE a Chile. Las importaciones de la UE provenientes de Chile se concentran en unas cuantas categorías, principalmente: las frutas y nueces comestibles, el $47 \%$ (esencialmente uva de mesa, manzanas y peras); las bebidas, el 20\% (esencialmente vinos), y los pescados y mariscos, el 12\% (esencialmente salmón) de las importaciones agroalimentarias de 2018. En contraste, las exportaciones agroalimentarias de la UE hacia Chile están más diversificadas, incluyendo: las bebidas, el 16\%; los vegetales y las frutas procesadas, el $12 \%$; otras preparaciones comestibles, el $11 \%$; los desechos de alimentos, el 10\%; los productos lácteos, el 8\%; y los cereales preparados, el $7 \%$ de las exportaciones agroalimentarias de 2018 (ver gráficos 4 y 5).

Particularmente impresionante ha sido el desarrollo, entre 2003 y 2008, de las importaciones de la UE desde Chile para la carne y los productos lácteos, la madera y sus derivados, las frutas y nueces comestibles, los pescados y mariscos, y las bebidas, a tasas promedio anuales de un $16,7 \%, 12,3 \%, 12,1 \%, 10,4 \%$, y $8,3 \%$, respectivamente (ver 
72 B. HENRY DE FRAHAN, C. HARTWELL y A. VALDÉS / Comercio agroalimentario UE-Chile

Gráfico 4. COMPOSICIÓN DE PRODUCTOS AGRÍCOLAS Y DE ALIMENTOS IMPORTADOS POR LA UE-28 DESDE CHILE, 2018

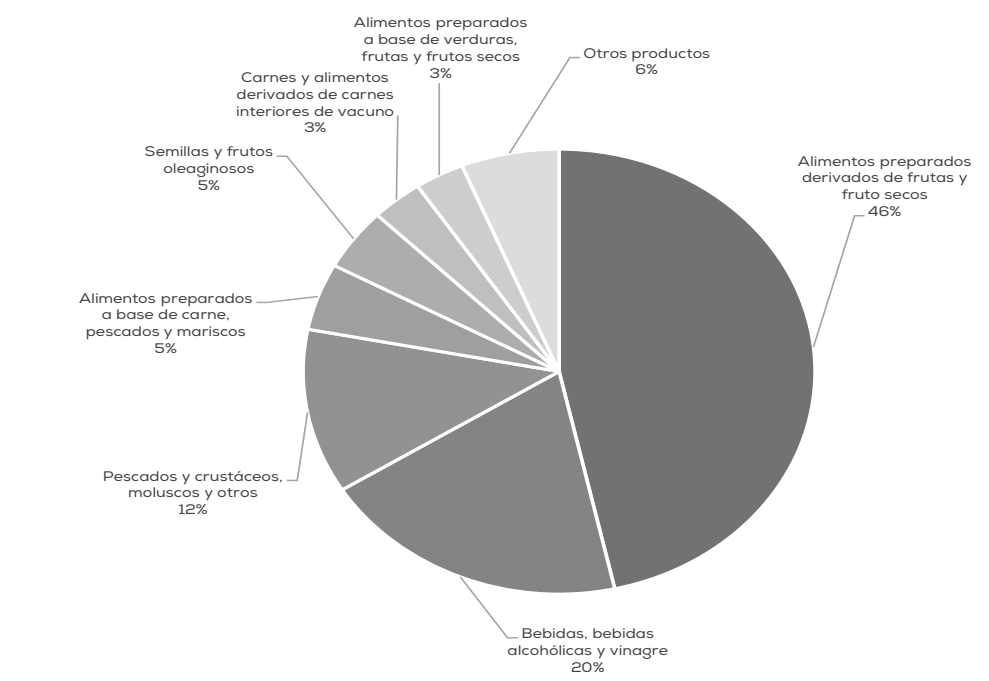

Fuente: Eurostat Comext.

Gráfico 5. COMPOSICIÓN DE PRODUCTOS AGRÍCOLAS Y DE ALIMENTOS EXPORTADOS POR LA UE-28 HACIA CHILE, 2018

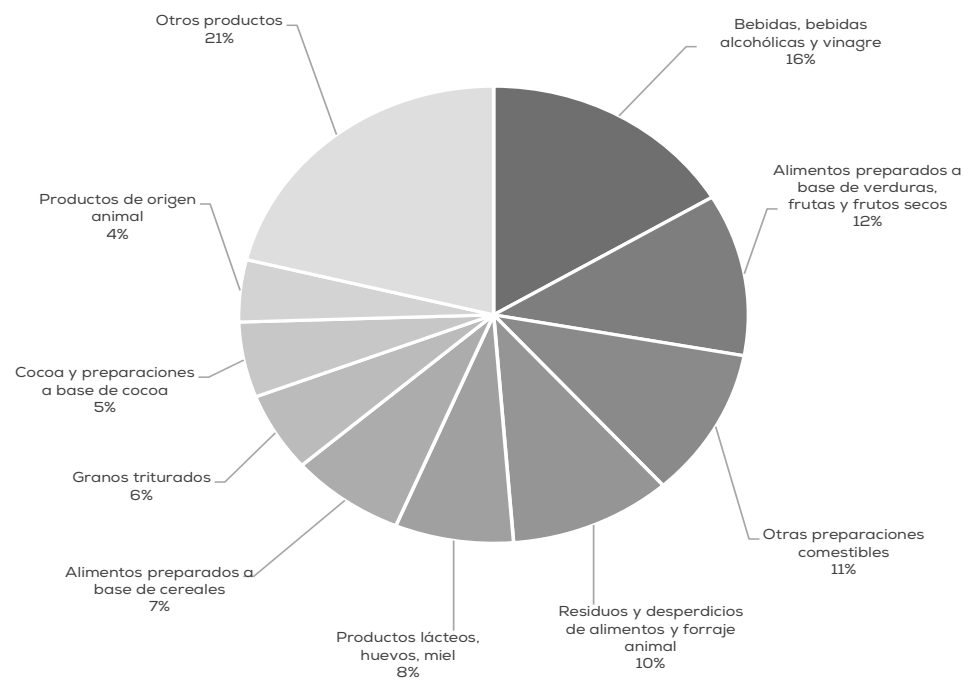

Fuente: Eurostat Comext. 
Gráfico 6). Desde el año 2008, las importaciones de la UE desde Chile solo han continuado su incremento para las frutas y nueces comestibles, las bebidas y los pescados y mariscos, a tasas promedio anuales de un $4,2 \%, 1,2 \%$ y $0,9 \%$, respectivamente, mientras que las importaciones de la UE desde Chile han disminuido para la madera y sus derivados, la carne y los productos lácteos, a tasas promedio anuales de un $-1,4 \% \mathrm{y}$ $-2,8 \%$, respectivamente. Aunque representan una pequeña parte de las importaciones de los productos agroalimentarios de la UE desde Chile, a partir del año 2008 las importaciones de los vegetales preparados, las frutas y nueces, y los aceites de oliva y frutos oleaginosos, han crecido a unas considerables tasas promedio anuales de un 13\% y 19\%, respectivamente.

\section{Gráfico 6. COMPOSICIÓN DE IMPORTACIONES AGRÍCOLAS, DE ALIMENTOS Y} FORESTALES DE LA UE-28 DESDE CHILE, 2000-2018

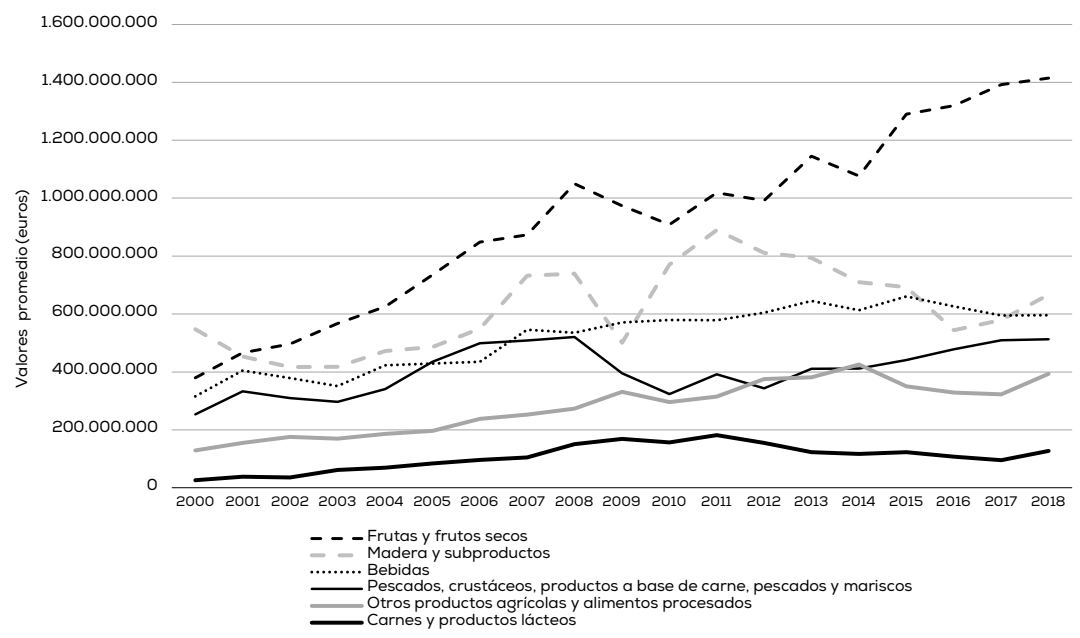

Fuente: Eurostat Comext.

En comparación con sus competidores directos en el hemisferio sur, el desempeño exportador de Chile en la UE ha sido impresionante. Al medir el desempeño exportador como la proporción del ICR de Chile con la UE en relación al ICR de un competidor con la UE para la misma categoría de producto y tiempo (ver el Apéndice para la metodología), los productos agrícolas y alimentarios chilenos en el mercado de la UE superaron, a partir del año 2003, las exportaciones de Argentina, 
Brasil, Perú y Sudáfrica, coincidiendo con el período de vigencia del Acuerdo de Asociación (ver Gráfico 7). Llama la atención que Chile ha estado por bajo las exportaciones provenientes de México durante un breve período de seis años, a partir de 2008, el mismo año en que México ingresó a una 'asociación estratégica' con la UE (Schade 2019).

Gráfico 7. ÍNDICES DE COMERCIO RELATIVOS DE TODAS LAS EXPORTACIONES CHILENAS AGRÍCOLAS Y DE ALIMENTOS (HS 01-24) HACIA LA UE, COMPARADAS CON CINCO PAÍSES, 2000-2018 (2003 = 100)

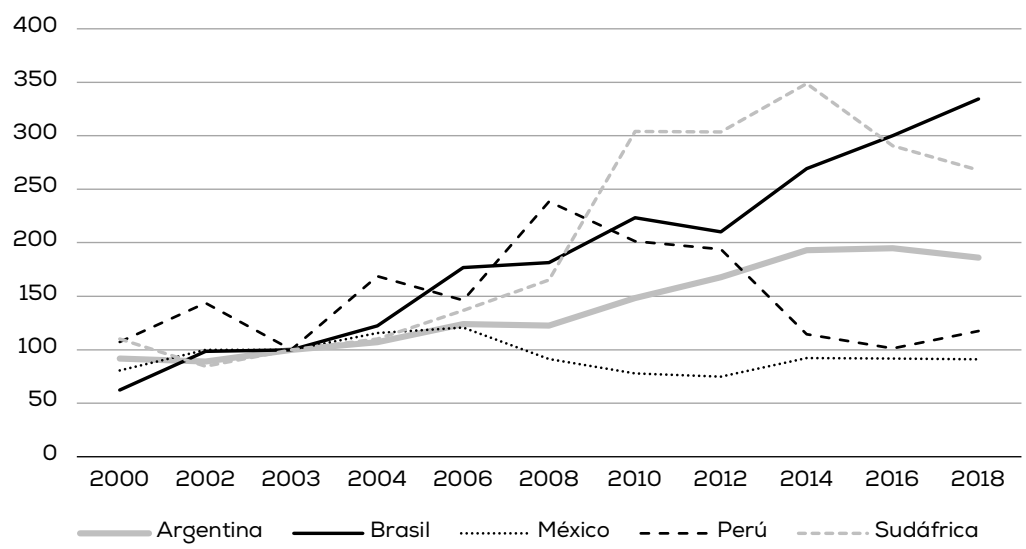

Fuente: Eurostat Comext.

\section{LOS PRINCIPALES IMPULSORES DEL COMERCIO AGROALIMENTARIO BILATERAL}

Desde la entrada en vigencia del Acuerdo de Asociación entre la UE y Chile, esta performance comercial se ha visto impulsada por varios factores, siendo algunos más importantes que otros. En primera instancia, la crisis financiera global de los años 2007-2008 hirió mucho más a Chile en su capacidad exportadora a la UE que a la inversa, mientras que la consiguiente crisis europea empantanaba la demanda de la UE por importaciones. Estas circunstancias macroeconómicas pueden explicar la ralentización del comercio bilateral entre Chile y la UE que ha persistido desde el año 2008, en tanto el valor total de las importaciones de la UE desde Chile, de hecho, disminuyó un $40 \%$ entre 2007 y 2009 , y luego, nuevamente, en un 35\% entre 2011 y 2016. La ralentización 
de la tasa de crecimiento de las importaciones de la UE de productos agroalimentarios chilenos posterior a 2008, probablemente también está relacionada con un menor crecimiento económico en Chile (debido a los menores precios del cobre, la principal exportación de Chile) y a un crecimiento más lento de la demanda asociada para estos productos en la UE.

El segundo impulsor clave del comercio entre la UE y Chile también ha sido macroeconómico, a saber, la fluctuación de la tasa de cambio nominal entre las monedas europeas y los pesos chilenos, la que se ha manifestado en las volátiles importaciones hacia la UE desde Chile para todos los bienes $\mathrm{y}$, en menor medida, para los productos agrícolas y alimentarios durante todo el período. Los incrementos del valor en euros de las importaciones de la UE durante los períodos 2003-2006 y 2009-2011 correspondían, de hecho, a períodos de apreciación del peso chileno en relación al euro, mientras que los declives en las importaciones de la UE durante los períodos 2007-2009 y 2011-2015, correspondían a períodos de depreciación del peso chileno en relación al euro.

El tercer factor, principal para nuestros propósitos y tal vez el más importante bajo el control de los decisores políticos en ambos socios comerciales, se relaciona con la celebración con terceros de acuerdos comerciales de nueva generación durante los años posteriores a la entrada en vigencia del Acuerdo de Asociación Chile-UE. Como fue indicado en las secciones previas, es del todo posible que estos acuerdos adicionales puedan haber desviado el comercio bilateral entre Chile y la UE hacia terceros mercados (ECORYS-CASE 2017). De hecho, la evolución de los índices de comercio relativo muestra que este es el caso, en tanto el ICR para todos los bienes entre la UE y Chile, desde el año 2009 al 2018, se deterioró en mayor medida para el total de las exportaciones de Chile a la UE, que para el total de las exportaciones de la UE hacia Chile. Además, es importante notar que el ICR de las exportaciones de productos agrícolas y alimentarios de Chile a la UE también se deterioró a partir de 2009.

A esta desviación del comercio ha contribuido la apertura, relativamente limitada, de los mercados domésticos de la UE a las importaciones agrícolas desde Chile en comparación a los mercados relativamente más abiertos para las importaciones desde la UE. Sin lugar a dudas, la entrada en vigencia del Acuerdo de Asociación de 2003 mejoró (gra- 
dualmente) el acceso a mercados para las exportaciones chilenas agrícolas y alimentarias en la UE en comparación con la situación en que estaban previo al acuerdo. Sin embargo, a 2018 (15 años después de la entrada en vigencia del AA) aún había 502 líneas arancelarias entre las 2.354 líneas arancelarias de productos agrícolas y de alimentos presentes en el HS 2002 (o un 21\% del total) que estaban excluidas de esta gradual liberalización de las importaciones, principalmente para productos hortícolas, lácteos y de pesca, para el aceite de oliva y para otros alimentos procesados. Unas 110 líneas arancelarias adicionales (4,7\% del total) se encuentran bajo liberalización parcial, mayoritariamente para algunas frutas y vegetales, otros productos lácteos, productos derivados del azúcar y el cacao, y algunas preparaciones a base de productos agrícolas. Finalmente, otras 283 líneas arancelarias (o el 12\% del total) cuentan con una tariff rate quota (TRQ) para las carnes (vacuno, cerdo, aves de corral, ovinos y caprinos), los quesos, los cereales, el ajo, los hongos y trufas, las guindas en conserva y los alimentos procesados que contienen azúcares (confiterías, preparaciones a base de chocolate, bizcochos y waffles), y algunos productos provenientes de la merluza, el salmón y el atún. El bajo nivel de utilización de las TRQ, que la UE garantizó para varias carnes durante 2015 (al igual que en 2013 y 2014), probablemente se debe a un conjunto de factores, incluyendo: el menor crecimiento en la demanda de importaciones en la UE y la reducción de importaciones provenientes de distintas fuentes (aproximadamente desde 2008); condiciones climáticas desfavorables para el aprovisionamiento de carnes de vacuno, caprinos y ovinos durante esos años; el reestructuramiento de parte de Chile de los Planteles Bajo Certificación Oficial (PABCO - los holdings que trabajan con animales bajo certificación), un sistema de certificación de carnes para las exportaciones a la UE; un incremento en la demanda chilena interna por estos productos; y el desvío de exportaciones a otros destinos (particularmente hacia los mercados asiáticos debido al mayor atractivo de sus precios). Para las otras categorías de productos sujetos a cuotas de importación, desde el año 2006 apenas han tenido lugar exportaciones a la UE, excepto por pequeños volúmenes de ajo y de confites sin cacao.

Parece que en los subsectores para los que se ha mantenido una alta protección de parte de la UE (carne, lácteos, productos del mar y algunos productos hortícolas), las importaciones de la UE desde Chi- 
le se han estancado desde 2008. Mientras que en los subsectores para los que se ha mantenido una baja protección de la UE (por ejemplo, las frutas y nueces comestibles, las preparaciones de vegetales y las bebidas), las importaciones de la UE desde Chile han ido en constante aumento (ver Gráfico 6). Sin embargo, es difícil generalizar por subsectores debido a los distintos niveles de protección desde la UE dentro del mismo subsector y a los variados factores en juego. Un análisis cuantitativo en mayor profundidad necesitaría determinar si un elevado nivel de protección de la UE se corresponde con un pobre desempeño importador de la UE.

Más allá del problema de los aranceles restantes, también existe un fuerte componente de BNA al comercio agrícola entre Chile y la UE. En particular, los requerimientos SFS pueden dificultar el acceso al mercado para algunas de las exportaciones agrícolas y de alimentos de Chile en la UE, creando pérdidas irrecuperables de eficiencia (deadweight losses), similares a las observadas en otros lugares del mundo (Rickard y Lei 2011). Según lo planteado por la Asociación de Exportadores de Frutas de Chile (Asoex), Chile, en su subsector exportador clave - las frutas frescas - ha presentado pocos problemas en el acatamiento del estándar de calidad y las regulaciones SFS requeridas por la UE (Araya y Caballero 2016). Esta es también la opinión de la Asociación Chilena de Exportadores de Carne (Chile Carne) en relación al creciente subsector exportador de las carnes de aves de corral y de cerdo (Sepúlveda 2016). Sin embargo, existe una alta sensibilidad de parte de los exportadores agrícolas chilenos hacia cualquier cambio en las reglas SFS de la UE concernientes a la fruta (Melo et al. 2014), una sensibilidad compuesta por variadas y considerables deficiencias en el sistema de control de exportaciones chileno, incluyendo la trazabilidad y los procedimientos de certificación.

Un ejemplo de las consecuencias de este problemático sistema tuvo lugar el año 2013, cuando las autoridades chilenas voluntariamente suspendieron la certificación de exportaciones de carne de vacuno destinadas a la UE a partir de una inspección de parte de la Oficina de Alimentos y Animales de la Comisión Europea (European Comission 2013a; Perucho 2016). A partir de esa suspensión, solo un limitado grupo de holdings chilenos exportadores de carne de vacuno se han registrado y certificado bajo el — supuestamente reforzado - programa 
PABCO Vigente UE para las exportaciones de carne de vacuno fresca a la UE (European Comission 2013b). Sin embargo, las deficiencias del sistema chileno no solo han dañado a los exportadores, sino que también han creado confusión en las importaciones: a pesar de que finalmente en 2013 Chile levantó sus prohibiciones sobre las importaciones de carne de vacuno de la UE (debido a la encefalopatía espongiforme bovina, EEB, anteriormente observada en la UE), hasta hace poco tiempo atrás aún no le estaba permitido a la UE exportar carne de vacuno a Chile debido a requerimientos específicos establecidos en la legislación chilena (Coronas-Balsera 2016; Mériaux 2016; Perucho 2016). Estos requerimientos establecían la identificación de los cortes de carne importados de acuerdo a una nomenclatura específica y a una clasificación adicional para los cuerpos de los bovinos, utilizando una terminología y criterios distintos de los aplicados en la UE.

\section{LAS OPORTUNIDADES COMERCIALES DE UNA MODERNIZACIÓN DEL ACUERDO DE ASOCIACIÓN ENTRE LA UE Y CHILE}

Considerando estas barreras aún existentes, es probable que la modernización del Acuerdo de Asociación UE-Chile del año 2002 se enfoque en la superación de los problemas relacionados con las restricciones de la UE sobre los productos agrícolas y alimentarios sensibles, y en los flujos de servicios e inversiones. La modernización del AA también debería encontrar caminos que reduzcan las barreras no arancelarias imperantes para el acceso de productos a mercados no-agrícolas (AMNA), en tanto las barreras arancelarias comerciales para estos productos prácticamente han sido removidas con la implementación del Acuerdo de Asociación del año 2002.

Respecto de la importante categoría de las exportaciones de fruta fresca a la UE, el problema más complejo de la expansión chilena en el mercado de importaciones de la UE es lograr satisfacer las distintas demandas específicas de los retailers europeos, como las cadenas de supermercados, las que tienen sus propios estándares de certificación (Araya y Caballero 2016). Estos estándares han sido internalizados y adoptados por los cultivadores y exportadores comerciales chilenos, pero con un costo adicional, principalmente debido a la diversidad presente a lo largo de los Estados miembros de la UE y de los retailers. 
En respuesta a este problema, la Asociación de Exportadores de Fruta de Chile (ASOEX) ha comenzado el programa de Buenas Prácticas Agrícolas de Chile (BPA) para ayudar a los productores y a los exportadores chilenos de frutas y vegetales a cumplir con los múltiples requerimientos privados establecidos desde distintos retailers extranjeros. El programa de BPA chileno busca facilitar la certificación de parte de distintas agencias de certificación privadas (Global GAP; British Retail Consortium, BRC; Rainforest Alliance; Hazard Analysis and Critical Control Points, HACCP; Global GAP Risk Assessment on Social Practice, GRASP; los retailers Tesco y Walmart, entre otras).

La consecuencia de la autosuspensión chilena de exportaciones de carne de vacuno fresca a la UE del año 2013 se sintió profundamente en la industria. El stock de animales bovinos cayó considerablemente, influenciado también por la competición en algunas regiones por el uso del suelo para otros productos (por ejemplo, lácteos, cereales, frutas y bosques), siendo esto más patente en la Región de la Araucanía. Los representantes de la Feria de Ganaderos de Osorno (Fegosa), sin embargo, son optimistas respecto de que Chile en los próximos años recuperará sus volúmenes de exportaciones a la UE, la que es considerada por la asociación como un destino atractivo para sus exportaciones (Jurgensen 2016). Anticipándose a este potencial futuro, estos representantes verían con buenos ojos una expansión de la cuota de importaciones de Chile sin especificaciones para la carne de vacuno en la UE, para alcanzar las 8.000 toneladas por año a partir de la cuota de importaciones del año 2016 de 2.250 toneladas. Los niveles actuales de la cuota añaden incertidumbre en relación a la capacidad de recuperar las inversiones de entrada asociadas a la búsqueda de compradores y al establecimiento de las cadenas de marketing necesarias para una posible expansión hacia los mercados europeos.

De acuerdo a la Asociación de Exportadores de Carne de Chile, el bajo nivel de las cuotas de importación de la UE, sin especificaciones para las carnes de aves de corral y de cerdo, es la principal limitante de las exportaciones de Chile en la UE, y no así los requerimientos sanitarios de la UE. Aunque las cuotas de importación sin especificaciones del año 2016, de 16.675 toneladas de carne de aves de corral y de 8.050 toneladas de carne de cerdo, no han sido cumplidas desde 2014 y 2013, respectivamente, debido a mejores oportunidades en otros mercados, 
Chile Carne considera que la eliminación o, en su lugar, la expansión de estas cuotas de importación en el contexto de la modernización del Acuerdo de Asociación UE-Chile puede generar una mayor certeza para las inversiones de los subsectores exportadores chilenos de las aves de corral y de cerdo destinados a la UE.

Dados los actuales niveles de exportaciones desde Chile a la UE, la cuota de importación de 2016 de 7.600 toneladas para ovinos y caprinos sin especificaciones, no es en la actualidad una restricción significativa para las exportaciones chilenas a la UE. En los últimos años ha tenido lugar una considerable desviación de las exportaciones, con un creciente volumen de las exportaciones chilenas dirigiéndose a los mercados asiáticos. Chile, sin embargo, cuenta con el potencial para incrementar sus provisiones de ovinos y caprinos para la UE, pero está sujeto al desgaste (Mériaux 2016). En Magallanes, la principal región productora de ovinos y caprinos, se aplica el sistema de trazabilidad PABCO, con cobertura para prácticamente el volumen completo de animales.

Entre los productos lácteos, la UE ofreció una cuota de importación libre de impuestos para el queso, la que alcanzaba las 2.475 toneladas para cerca de 30 líneas arancelarias en 2016; esto, a pesar de que aún protege sus otras categorías de lácteos con aranceles muy elevados y específicos. Chile apenas ha usado esta cuota de importación libre de impuestos para el queso, especializándose en la producción de suero, por el que se podría beneficiar bastante al recibir nuevos accesos a mercados (Contreras 2016).

El Acuerdo de Asociación UE-Chile ha jugado un rol importante y positivo en la expansión de las exportaciones de vino desde Chile a la UE. Las exportaciones de vinos chilenos a la UE enfrentan aranceles sin impuesto ad valorem, y sin especificaciones particulares ni cuotas de importación en la UE. Reino Unido (UK), pero también los países escandinavos, Holanda y algunos de los restantes Estados miembros de la UE, son los principales mercados exportadores para el vino chileno. En el futuro, un problema importante para la industria del vino en Chile se concentra en las implicaciones para el acceso a mercados en UK como consecuencia del proceso del Brexit (Soler 2016).

Mientras que, como resultado del Acuerdo de Asociación UE-Chile del año 2002, la UE redujo el grado de las especificaciones ad valorem 
en las importaciones sobre varios productos de alimentos procesados, mantuvo elevadas especificaciones particulares para una variedad de productos alimentarios (por ejemplo, los jugos de frutas y el aceite de oliva) importados desde Chile, sin garantizar cuotas de importación libres de impuestos. Estas elevadas especificaciones particulares (por ejemplo, 1.245 euros por kilo de aceite de oliva) contrastan con el trato preferencial dado a los países del Magreb y otros sobre los mismos productos de alimentos, mientras que Chile ha desarrollado una ventaja comparativa para esos mismos productos (Moglia 2016). Para otros grupos de productos de alimentos procesados (por ejemplo, confitería sin cacao, preparaciones de chocolate, y biscochos y waffles) la UE ofreció cuotas de importación libres de impuestos para pequeños volúmenes (aproximadamente entre 400 y 500 toneladas para cada uno de los tres productos de alimentos procesados desde el año 2003). Esto implica una incertidumbre considerable para las compañías exportadoras individuales, desincentivando el marketing hacia la UE, ya que estos exportadores individuales compiten por entrar dentro del límite de la cuota y se arriesgan a pagar un alto impuesto una vez que la cuota ha sido totalmente utilizada.

Aún se aplican las cuotas arancelarias a varios productos frescos provenientes de la merluza, el salmón (seco, salado y ahumado) y el atún. Las cuotas de importación libre de impuestos se aplican a 5.000 toneladas de merluza fresca y a 40 toneladas de salmón procesado. Una cuota importante se aplica a 150 toneladas de productos de atún en conserva con un impuesto aduanero preferencial de un tercio del impuesto de la Nación Más Favorecida (NMF). No obstante, Chile cuenta con una floreciente industria para el pescado y los mariscos que estima, según los datos más recientes, el valor de las exportaciones chilenas para los productos del pescado y los mariscos en 4,4 billones de dólares anuales. Chile es también el segundo proveedor más grande a nivel mundial de salmón atlántico de piscicultura. Y se cree que los mejoramientos en infraestructura y el aumento de la inversión en los sectores de pesca y acuicultura son los factores que más han influido en el rápido crecimiento de esta industria (Bacigalupo y Rojas 2016).

Los principales productos forestales exportados por Chile a la UE consisten en la pulpa, el aserrín y los paneles de madera de pino y eucaliptus. Las exportaciones de estos productos forestales a la UE 
enfrentan aranceles sin impuestos ad valorem, y ninguna especificación particular ni cuotas de importación en la UE. Lo que se requiere es que las exportaciones chilenas cumplan con las certificaciones de la UE según la Timber Regulation de la misma UE (Raga y Arana 2016).

En contraste, la estructura de aranceles de importaciones de Chile es simple y transparente. La mayoría de los aranceles a los que se enfrentan las importaciones de la UE en Chile están por bajo un arancel del $2 \%$ para prácticamente todas las importaciones de las categorías agrícolas y de alimentos, exceptuando los productos lácteos (5\%). Sin embargo, algunos problemas importantes, recurrentemente discutidos por el Comité de Manejo Conjunto de Asuntos SFS, han sido los siguientes: la prohibición, por varios años activa, de las importaciones de carne de vacuno de la UE a Chile como resultado de la enfermedad de la EEB en la UE; los requerimientos específicos establecidos en la ley chilena de la carne y que han impedido que tengan lugar las importaciones de carne de vacuno proveniente de la UE; y la definición de las condiciones fitosanitarias de importación de Chile para los frutos y los vegetales frescos desde la UE. Por ello, en el contexto de la modernización del Acuerdo de Asociación del año 2002, las principales preocupaciones de parte de la industria europea se centrarían en los problemas SFS para las frutas y los vegetales frescos, y en los problemas de las barreras técnicas al comercio (BTC) para las carnes. Prácticamente a ninguna importación de frutas y vegetales frescos (con la excepción del kiwi) provenientes de la UE se le ha permitido aterrizar en el mercado chileno. Para la European Fresh Produce Association (Freshfel) de hecho existe un potencial de exportación para las frutas y los vegetales provenientes de la UE que, habiendo sido almacenados con posterioridad a la cosecha, sean vendidos durante el período fuera de temporada de ese producto en Chile (Binard 2016). De modo similar, durante varios años ninguna importación de carne de vacuno proveniente de la UE ha sido autorizada en Chile. Para la European Livestock and Meat Trading Union (UECBV), hay sin embargo un fuerte interés en exportar carne de ternera entre las carnes de vacuno provenientes de Bélgica, Francia y Holanda hacia Chile (Mériaux 2016). Y también hay interés en Bélgica, Francia y España por obtener una mayor ventaja sobre las variaciones por temporadas del precio y el suministro entre la UE y Chile para exportar más carne de cerdo fresca a Chile. 
Sin embargo, a pesar de estas oportunidades de comercio, al momento en que escribimos este texto, las negociaciones en curso entre la UE y Chile sobre la modernización del Acuerdo de Asociación avanzan muy lentamente. Este retraso se debe, en gran medida, al resultado de los recientes requerimientos de parte de la UE en relación a las indicaciones geográficas (IG), las que identifican el origen de bienes agrícolas o productos alimenticios de una localidad o región particular y en donde una cualidad dada, $u$ otras características de producto, son atribuidas esencialmente a su región geográfica. Esta medida quizás esté en marcha para usar a Chile como un caso de prueba, o como un precedente, para señalar de modo creíble la posición negociadora de la UE sobre este tema en las futuras conversaciones con otros socios comerciales. En el caso de Chile, estos IG se concentran en los productos agrícolas y en los agroprocesados de origen agrícola. En realidad, las IG pueden constituir otra barrera al comercio, incluso cuando en el nuevo acuerdo se reduzcan los aranceles, ya que el requerimiento de las IG puede erosionar el valor de las preferencias.

Tal vez más problemático que la insistencia en las IG, es el hecho de que los recientes requerimientos de la UE han ampliado la lista de las indicaciones geográficas protegidas. La base legal para las IG en el Acuerdo de Asociación del año 2002 era que las dos partes accedieran a ajustarse a los estándares internacionales. Pero, según las conversaciones sostenidas con representantes del gobierno de Chile, los requerimientos actuales de la UE en la negociación en curso con Chile van más allá de los estándares anteriormente establecidos y, en opinión de la industria, estos requerimientos más rigurosos podrían reducir significantemente las exportaciones chilenas de un conjunto de productos agrícolas.

El caso del etiquetado del queso resulta revelador respecto de la complejidad asociada a la satisfacción de los recientes requerimientos de la UE. La lista de la UE de IG incluye 222 productos, de los cuales 68 (casi un tercio) son quesos. Con un etiquetado adecuado, para muchos productos agrícolas la indicación geográfica es más bien sencilla de identificar. Por ejemplo, el Prosciutto di Modena, el Camembert de Normandía, el Aceite de la Rioja o el vino blanco producido en Alsacia, todos son claramente identificables con sus regiones. Pero las nuevas IG para el queso podrían incluir nombres genéricos como Camembert, Feta, Gruyère, Gouda y Roquefort, que son tipos de queso genéricos, por lar- 
go tiempo llamados por estos nombres, y que en la actualidad son producidos en varios países, incluido Chile. Bajo la actual posición de la UE, en Chile el queso no podría seguir con su producción bajo esas etiquetas. De hecho, para que el queso sea promocionado según esas etiquetas, tendrían que haber sido importados desde la UE. ¿Le estaría permitido a Chile producir y exportar los productos mencionados a terceros países como China? No si ellos son etiquetados como producidos en Chile. ${ }^{3}$

Hay algunos otros problemas sin resolver, pero estos tienen una menor relevancia directa para la agricultura. Por ejemplo, hacer cumplir los requerimientos de la UE respecto de los derechos de propiedad intelectual que afectan a los productos farmacéuticos probablemente reduciría su disponibilidad en Chile. También, en relación a la inversión extranjera directa (IED), la UE ha solicitado la creación de un tribunal para la resolución de disputas, el cual se enfoca en las IED de la UE en Chile, pero que sería irrelevante para Chile considerando su insignificante nivel de IED en la UE.

\section{CONCLUSIONES}

La relación económica entre Chile y la UE es importante para ambos socios, aunque fue afectada por la crisis global financiera de los años 2007-2008, tanto en Chile como en la UE. En términos absolutos, el comercio bilateral de productos agrícolas y de alimentos ha crecido para ambos socios desde la entrada en vigencia del Acuerdo de Asociación de 2002 (a una tasa promedio anual del 14\% de las exportaciones desde la UE hacia Chile y de un 4\% de las importaciones de la UE desde Chile), con un incremento mucho mayor en las exportaciones de la UE entre los años 2009 y 2018, que entre 2003 y 2009 (un incremento nominal anual de un $17 \%$ versus un $7 \%$ ), y un incremento mucho menor en las importaciones de la UE entre los años 2008 y 2019 que entre 2003 y 2008 (un incremento nominal anual del 2\% versus el 11\%). Sin embargo, en términos relativos, al comparar el comercio con el resto del mun-

\footnotetext{
${ }^{3}$ Como dato interesante, Chile importa algo de queso feta con IG de Grecia, aunque el producto tiene su origen en Dinamarca. Esto resulta revelador ya que sugiere que la UE es incapaz de controlar totalmente las IG, incluso dentro de sus límites oficiales, pero la UE sin embargo demanda que se apliquen IG a las exportaciones desde Chile hacia terceros.
} 
do, la imagen es un poco más sutil, con un alza en términos relativos de las exportaciones chilenas de productos agrícolas y alimentarios hasta 2009, y una disminución a partir de ahí, y con las exportaciones de la UE bajando hasta 2009 y luego mejorando hasta 2017.

El acceso a mercados para las exportaciones agrícolas y de alimentos desde Chile hacia la UE ha mejorado gracias al Acuerdo de Asociación de 2002, principalmente a través de la apertura gradual de cuotas de importación y de la reducción de barreras para cerca de 400 líneas arancelarias (o el 17\% del total) en productos agrícolas y de alimentos clave. Sin embargo, aún hay cerca de 500 líneas arancelarias (o el 21\% del total) de productos agrícolas y de alimentos que están excluidas de esta gradual liberalización de importaciones. Además de sus exportaciones tradicionales, Chile aún cuenta con un mayor potencial exportador hacia la UE, pero solo bajo un programa de liberalización progresivo, o total, para las carnes de vacuno, cerdo y de aves de corral, el aceite de oliva, los jugos de fruta y algunos productos lácteos y de pesca específicos. Las tariff rate quotas garantizadas por la UE, las cuales no han sido totalmente utilizadas para las carnes de vacuno y de cerdo desde el año 2013, y para los productos avícolas y el ajo desde 2014, se deben, principalmente, a las mejores oportunidades y menores incertidumbres para Chile en otros mercados, especialmente en China. Las limitaciones por el lado de la oferta, en particular para la producción de ganado, merece atención adicional. Esto, debido a que la mayor parte de las exportaciones chilenas agrícolas y de alimentos no son mercancías en el sentido tradicional de productos a granel, homogéneos, como los cereales o las semillas de olivos, las BTC y las medidas SFS también juegan un rol relevante en el acceso a mercados hacia la UE.

A pesar de los bajos aranceles aplicados por Chile a las importaciones de productos agrícolas y de alimento provenientes de la UE, el acceso a mercados para algunas exportaciones agrícolas y de alimentos específicas de la UE - como las exportaciones de vacuno, las frutas frescas y los vegetales - ha sido negado durante años debido a problemas asociados a los aspectos sanitarios y fitosanitarios, y a otros requerimientos específicos. Los potenciales exportadores de la UE hacia Chile se concentran en las frutas y vegetales para el período comercial de fuera de temporada chileno, y también en productos de carne de vacuno y de cerdo, además de las exportaciones actuales. 
La modernización del Acuerdo de Asociación del año 2002 que está siendo negociada en la actualidad entre la UE y Chile ofrece una oportunidad para alcanzar este potencial comercial bilateral. Las actuales negociaciones, sin embargo, se encuentran retrasadas por varias condicionalidades propuestas por la UE, siendo la más importante de ellas el reconocimiento de distintas indicaciones geográficas de la UE para los productores y exportadores chilenos.

\section{BIBLIOGRAFÍA}

Borregaard, N. 2004. Trade Liberalization in Chile: What Is the Evidence of Its Effects and How Can Sustainable Development Be Safeguarded? Working Group on Development and Environment in the Americas, Discussion Paper DP05, Tufts University. Disponible en: http://citeseerx.ist.psu.edu/viewdoc/ download?doi=10.1.1.367.1631\&rep=rep1\&type=pdf [18 de abril 2020].

Dür, A. 2007. EU Trade Policy as Protection for Exporters: The Agreements with Mexico and Chile. Journal of Common Market Studies 45(4), 833-855.

ECORYS-CASE 2017. Ex-Ante Study of a Possible Modernisation of the EU-Chile Association Agreement. Luxembourg: Publications Office for the European Union.

European Commission 2013a. Final Report of an Audit Carried out in Chile from 18 February to 1 March 2013 in order to Evaluate the System of Controls over the Production of Fresh Beef Meat, Ovine and Porcine Meat, Meat Products and Casings Destined for Export to the EU, as well as Certification Procedures. DG (SANCO) 2013-2865 - MR Final, Health and Consumers Directorate-General of the European Commission.

European Commission 2013b. Final Report of an Audit Carried out in Chile from 29 November to 10 December 2013 in order to Evaluate the Follow-up Action Taken by the Competent Authorities with Regard to the System of Controls over the Production of Fresh Beef Meat Destined for Export to the EU, as well as Certification Procedures. DG (SANCO) 2013-7189 - MR Final, Health and Consumers Directorate-General of the European Commission.

Foster, W. y Valdés, A. 2015. Measuring the Size of the Renewable Resource Sector: The Case of Chile. World Food Policy Journal 2(1), 19-35.

García, M. 2011. Incidents along the Path: Understanding the Rationale behind the EU-Chile Association Agreement. Journal of Common Market Studies 49(3), 501-524.

Horn, H., Mavroidis, P.C. y Sapir, A. 2010. Beyond the WTO? An Anatomy of EU and US Preferential Trade Agreements. The World Economy 33(11), 1565-1588.

Jean, S., Mulder, N. y Ramos, M.P. 2014. A General Equilibrium, Ex-Post Evaluation of the EU-Chile Free Trade Agreement. Economic Modelling 41, $33-45$.

Kjöllerström, M. 2006. The Special Status of Agriculture in Latin American Free Trade Agreements. Région et Développement 23, 73-106. 
Melo, O., Engler, A., Nahuehual, L., Cofre, G. y Barrena, J. 2014. Do Sanitary, Phytosanitary, and Quality-Related Standards Affect International Trade? Evidence from Chilean Fruit Exports. World Development 54, 350-359.

Nowak-Lehmann, F., Herzer, D. y Vollmer, S. 2007. The Free Trade Agreement between Chile and the EU: Its Potential Impact on Chiles's Export Industry. Applied Econometrics and International Development 7(1), 99-120.

OJEC 2002. Council Decision of 18 November 2002 on the Signature of an Agreement Establishing an Association between the European Community and its Member States, of the one part, and the Republic of Chile, of the other part. Official Journal of the European Community (OJEC), L352/1-1439.

Rickard, B.J. y Lei, L. 2011. How Important Are Tariffs and Nontariff Barriers in International Markets for Fresh Fruit? Agricultural Economics 42(s1), 19-32.

Schade, D. 2019. Of Insiders and Outsiders: Assessing EU Strategic Partnerships in their Regional Context. International Politics 56, 375-394. Disponible en: https://link.springer.com/article/10.1057\%2Fs41311-017-0132-y [18 de abril 2020].

Valdés, A. y Foster, W. 2018. Agricultural and Rural Policies in Chile (291-308). En Josling, T., Meyers, W.H., and Johnson, T. (eds.), Handbook of International Food and Agricultural Policies. Vol. I: Policies for Agricultural Markets and Rural Economic Activity. Singapore: World Scientific Publishing.

\section{Entrevistas}

Araya, E. y Caballero, I. 2016. Entrevista. Asociación de Exportadores de Frutas de Chile (Asoex). Junio 2016.

Bacigalupo, H. y Rojas, P. 2016. Entrevista. Sociedad Nacional de Pesca (Sonapesca). Octubre 2016.

Binard, P. 2016. Entrevista. The European Fresh Produce Association (Freshfel). Octubre 2016.

Contreras, R. 2016. Entrevista. Oficina de Estudios y Políticas Agrarias (Odepa). Junio 2016.

Coronas-Balsera, C. 2016. Entrevista. The European Commission. Septiembre 2016.

Jurgensen, H. 2016. Entrevista. Feria de Ganaderos de Osorno (Fegosa). Junio 2016.

Mériaux, J.-L. 2016. Entrevista. European Livestock and Meat Trading Union (UECBV). Octubre 2016.

Moglia, G. 2016. Entrevista. Chile Oliva. Junio 2016.

Perucho, S. 2016. Entrevista. The European Commission. Octubre 2016.

Raga, F. y Arana, T. 2016. Entrevista. Corporación Chilena de la Madera (Corma). Octubre 2016.

Sepúlveda, N. 2016. Entrevista. Exportadores de Carne de Chile (Chile Carne). Octubre 2016.

Soler, C. 2016. Entrevista. Vinos de Chile. Octubre 2016. 


\section{APÉNDICE}

\section{Definición de los índices de comercio relativos}

Para controlar los efectos de las características del importador y del exportador, se construyeron y compararon distintos índices relativos de comercio (IRC) con el fin de comprender los flujos comerciales a partir de la creación del pacto comercial del Acuerdo de Asociación EU-Chile de 2002.

Defina $x_{i j k t}$ como la representación de un flujo de exportación desde el país $i$ al país $j$, en la categoría de producto $k$, en el año $t$. A continuación, defina este flujo bilateral comercial desde el exportador $i$ al exportador $j$ en relación al flujo bilateral comercial desde el exportador $i$, distinto del exportador $i$, hacia el mismo importador $j$ para definir la siguiente relación de flujos comerciales bilaterales entre los socios $i$ y $j$ :

$$
R_{i i i^{\prime} k t}=\frac{x_{i j k t}}{x_{i \prime j k t}}
$$

A través del tiempo, esta relación de flujos comerciales bilaterales puede, por tanto, reflejar en qué grado han evolucionado las exportaciones desde el exportador $i$ en comparación con otro exportador $i$ ' en el mercado importador $j$ para la categoría de producto $k$. Esta relación limpia el efecto de los posibles cambios en las características del importador $j$ sobre los flujos de importaciones.

De igual forma, defina el flujo comercial bilateral $x_{i j k t}$ desde el exportador $i$ al importador $j$ ', distinto del importador $j$, para la categoría de producto $k$ en relación al flujo comercial bilateral desde el exportador i', distinto del exportador $i$, hacia el mismo importador $j$ ', para definir la siguiente relación de flujos comerciales bilaterales entre los socios $i$ y $j$ :

$$
R_{i i{ }^{\prime} j^{\prime} k t}=\frac{x_{i j \prime k t}}{x_{i \prime \prime^{\prime} k t}}
$$

A través del tiempo, esta relación de flujos comerciales bilaterales puede, por tanto, reflejar en qué grado han evolucionado las exportaciones desde el exportador $i$, en comparación con las exportaciones desde 
otro exportador $i$ ', en el mercado importador j' para la categoría de producto $k$. Esta relación limpia así el efecto de los posibles cambios de las características del importador $j$ ' sobre los flujos de importaciones.

Definamos ahora la relación de estos dos flujos bilaterales relativos como una relación de relaciones de flujo bilateral (BR designa birelaciones):

$$
B R_{i i^{\prime} j^{\prime}{ }^{\prime} k t}=\frac{R_{i i{ }^{\prime} j k t}}{R_{i i^{\prime} j^{\prime} k t}}
$$

A través del tiempo, esta ratio de flujo bilateral de ratios puede, por tanto, reflejar en qué grado han evolucionado las exportaciones desde el exportador $i$ en comparación con las exportaciones de otro exportador $i$ ' en el mercado importador $j$ para la categoría de producto $k$, en comparación con el grado en que han evolucionado las exportaciones desde exportador $i$ en comparación con las exportaciones desde otro exportador $i$ ' en otro mercado importador $j$ ' para la misma categoría de producto $k$. Esta ratio de ratios, o diferencia-en-diferencias, no solo lava el efecto de los posibles cambios en las características de los importadores $j$ y $j$ ' sobre los flujos de importaciones, sino que también el efecto de los posibles cambios de las características de los exportadores $i$ y $i$ ' sobre los flujos de exportaciones.

El reporte de la evolución de esta relación de relaciones BR a través del tiempo $t$ se puede facilitar al reportarla como relativa a la BR cuando $t=2003$ como año de referencia. Ahora, por tanto, finalmente definamos BR en relación a su base (BRR designa bi-relaciones relativas):

$$
B R R_{i i^{\prime} j j^{\prime} k t / 2003}=\frac{B R_{i i i^{\prime} j j^{\prime} k t}}{B R_{i i^{\prime} j j^{\prime} k 2003}} * 100
$$

Esta relación relativa de relaciones $B R R_{i i^{\prime} j j^{\prime} k t / 2003}$ ahora se puede aplicar para las distintas definiciones de los exportadores $i$ y $i$, para las distintas definiciones de los importadores $j$ y $j^{\prime}$, y para las distintas categorías de productos $\mathrm{k}$, y se puede trazar en el tiempo $t$, en donde $t=$ $2000, \ldots, 2003, \ldots, 2015$. 
1. Análisis del flujo bilateral UE-Chile en productos agrícolas y alimentos

Si nos interesamos en la penetración o concentración de las exportaciones de Chile al interior del mercado importador de la UE en relación a su penetración o concentración en otros mercados importadores, la evolución del comercio de productos agrícolas y alimentos entre Chile y la UE se puede rastrear y analizar para $B R R_{i i^{\prime} j j^{\prime} k t / 2003}$, en donde:

- $\quad i=$ Chile; $i^{\prime}=$ Resto del mundo (por ejemplo, ni Chile ni la UE); $j$

$=\mathrm{UE} ; \mathrm{y} j^{\prime}=$ Resto del mundo (por ejemplo, ni Chile ni la UE).

- $\quad k=$ Harmonized System de 1996 (HS 01-24) o cualquier otra categoría de producto agroalimentario del HS 1996.

- $t=2000, \ldots, 2003, \ldots, 2015$.

Si nos interesamos en la penetración o concentración de las exportaciones de la UE en el mercado importador de Chile en relación a su penetración o concentración en otros mercados importadores, esta también puede ser rastreada y analizada para $B R R_{i i^{\prime} j j^{\prime} k t / 2003}$, en donde:

- $\quad i=\mathrm{UE} ; i^{\prime}=$ Resto del mundo (por ejemplo, ni la UE ni Chile); $j=$ Chile; y $j^{\prime}=$ Resto del mundo (por ejemplo, ni la UE ni Chile).

- $\quad k=$ Harmonized System de 1996 (HS 01-24) o cualquier otra categoría de producto agroalimentario del HS 1996.

- $t=2000, \ldots, 2003, \ldots, 2015$.

2. Análisis de los flujos bilaterales de productos agrícolas y de alimentos para los exportadores que compiten con las exportaciones de Chile en el mercado de importaciones de la UE.

Si nos interesamos en la penetración o concentración de las exportaciones de Chile en el mercado importador de la UE en relación a la penetración o concentración de un exportador competidor en otros mercados de importaciones, la evolución del comercio de productos agrícolas y de alimentos entre Chile y la UE en relación a la evolución del comercio de productos agrícolas y de alimentos entre este exportador competidor y la UE podría ser rastreada y analizada para $B R R_{c / i i^{\prime} j j^{\prime} k t}$ definida como:

$$
B R R_{c / i i^{\prime} j j^{\prime} k t}=\frac{B R_{c i^{\prime} j j^{\prime} k t}}{B R_{i i^{\prime} j j^{\prime} k t}} * 100
$$


en donde:

- $\quad c=$ Chile; $i=$ Argentina, Brasil, México, Perú o Sudáfrica; $i$ ' $=$ Resto del mundo (por ejemplo, ni la UE, ni el exportador $c$ o $i$ ); $j=$ UE; y $j^{\prime}=$ Resto del mundo (por ejemplo, ni el exportador $c$ o $i$, ni la UE).

- $\quad k=$ Harmonized System de 1996 (HS 01-24) o cualquier otra categoría de producto agroalimentario del HS 1996.

- $\quad t=2000, \ldots, 2003, \ldots, 2015$.

El reporte de la evolución de esta relación de relaciones $B R R$ a través del tiempo $t$ se puede facilitar al reportarla como relativa a la $B R R$ cuando $t=2003$ designa el año de referencia. Ahora, por tanto, definamos finalmente esta $B R R$ en relación a su base:

$$
B R R_{c / i i^{\prime} j j^{\prime} k t / 2003}=\frac{B R R_{c / i i^{\prime} j j^{\prime} k t}}{B R R_{c / i i^{\prime} j j^{\prime} k 2003}} * 100
$$

Esta relación de relaciones relativa $B R R_{c / i i \prime j j \prime k t / 2003}$ ahora puede aplicarse a distintas definiciones de los exportadores $i$ y $i$, a distintas definiciones de los importadores $j \mathrm{y} j$ ', y a distintas categorías de productos $k$ y ser rastreada en el tiempo $t$, en donde $t=2000, \ldots, 2003, \ldots$, 2015. EP 